\title{
Carcinoid Tumor: Advances in Treatment Options
}

\author{
Urwat T. Vusqa $^{1}$, Stuti Patel ${ }^{2}$, Mamoon Ur Rashid ${ }^{3}$, Deepika Sarvepalli ${ }^{4}$, Abu H. Khan ${ }^{5}$ \\ 1. Internal Medicine, Army Medical College, Rawalpindi, PAK 2. Internal Medicine, Gujarat Medical Education and \\ Research Society Medical College, Vadodara, IND 3. Internal Medicine, AdventHealth, Orlando, USA 4. Internal \\ Medicine, Guntur Medical College, Guntur, IND 5. Gastroenterology, AdventHealth, Orlando, USA
}

Corresponding author: Deepika Sarvepalli, sarvepalli.deepika@gmail.com

\begin{abstract}
Small bowel neoplasms are rare, accounting for only 3\%-6\% of all gastrointestinal neoplasms. Carcinoid tumors represent a large portion of these (20\%-30\%), making them the second most common small bowel malignancy after adenocarcinoma. Gastrointestinal carcinoids constitute $70 \%$ of all neuroendocrine tumors, and out of those, $42 \%$ originate in the small bowel. They are predominantly seen in older patients around the age of 65 years. From 1973 to 2004, there has been more than a fourfold increase in the incidence of carcinoid tumors. This can be probably due to increased diagnostic accuracy rather than an actual increase in the number of new cases. The workup of a suspicious case of gastrointestinal bleeding consists of esophagogastroduodenoscopy and/or colonoscopy, and other imaging tests including video capsule endoscopy and balloon-assisted endoscopy. Management of the tumors is dependent on the size and location of the lesion. Treatment options include surgery, endoscopic removal of tumors, and various immunotherapy and chemotherapeutic agents.
\end{abstract}

Categories: Internal Medicine, Gastroenterology, Hematology

Keywords: carcinoid tumor, neuroendocrine tumors, small bowel cancer, lower gastrointestinal bleed

\section{Introduction}

Small bowel neoplasms are uncommon, accounting for only 3\%-6\% of all gastrointestinal (GI) neoplasms. Carcinoid tumors represent the second most common (20\%-30\%) small bowel malignancy after adenocarcinoma. GI carcinoids constitute $70 \%$ of all neuroendocrine tumors (NETs), and out of those, $42 \%$ originate in the small bowel $[1,2]$. They are predominantly seen in older patients around the age of 65 years [3]. The incidence of NETs is rare, constituting $0.5 \%$ of all newly diagnosed malignancies [4].

From 1973 to 2004, there has been more than a fourfold increase in the incidence of carcinoid tumors [5]. This can be probably due to increased diagnostic accuracy rather than an actual increase in the number of new cases [2]. We present a case of a carcinoid tumor that presented with GI bleed and anemia. The patient had normal findings on esophagogastroduodenoscopy and colonoscopy and was provisionally diagnosed with malignancy on computerized tomography (CT) abdomen/pelvis with contrast.

Received 12/16/2019

Review began 12/26/2019 Review ended 01/11/2020 Published 01/13/2020

\section{() Copyright 2020}

Vusqa et al. This is an open access article distributed under the terms of the Creative Commons Attribution License CC-BY 3.0., which permits unrestricted use, distribution, and reproduction in any medium, provided the original author and source are credited.

\section{Case Presentation}

A 52-year-old otherwise healthy man presented to his primary care physician with complaints of bleeding per rectum for the past six days. He described the stools as dark in color and pasty in consistency. He also complained of colicky right lower quadrant abdominal pain. Physical examination was unremarkable except for mild generalized abdominal pain. He was found to have a hemoglobin of $9 \mathrm{mg} / \mathrm{dl}$, and was referred to the emergency room for evaluation. Further lab studies revealed iron deficiency anemia, and fecal occult blood was positive. Further, the patient underwent a CT abdomen/pelvis with contrast, which showed a $3.7 \times 3.7 \times$ $3.2 \mathrm{~cm}$ mesenteric mass in the right mid-abdomen with associated desmoplastic reaction and thickening of the surrounding distal ileum, highly suspicious of carcinoid tumor. The patient's serotonin and chromogranin levels were also reported to be elevated.

The patient was then started on venofer for his anemia. To locate the source of bleeding, the patient underwent esophagogastroduodenoscopy and colonoscopy. However, both tests failed to demonstrate a source of an active or recent GI bleed. The options of attempted biopsy with interventional radiology versus surgical exploration with resection of affected area and mass were discussed with the patient. Considering the patient's symptoms and iron deficiency anemia, surgery was performed with the patient's informed consent. The patient completed the course of venofer and underwent explorative laparotomy with segmental ileal resection and primary reanastomosis. Gross findings were significant for a large abnormal mass of mesentery of distal ileum with dilated and thickened overlying small bowel. There was no evidence of peritoneal implants or liver masses. Resected mass and tissue were sent for pathology. The pathology report confirmed the presence of multiple foci of well-differentiated grade 1 (G1) NET extending to the serosa and involving the mesenteric margins (Figure 1). Three out of ten lymph nodes were positive for metastatic NET with the largest lymph node measuring 1-2 cm in diameter. The tumor stage was consistent with pT4 and pN1. The early postoperative period was unremarkable, and the patient was recommended to follow up with 


\section{Cureus}

surgery and oncology.
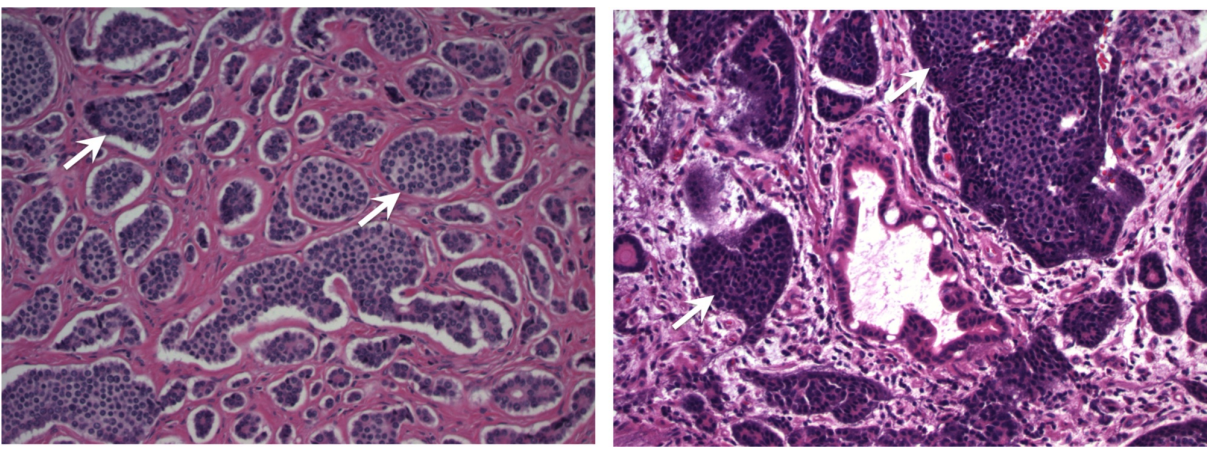

\section{FIGURE 1: Multiple foci of grade 1 (G1) well-differentiated NET extending into serosa and involving mesenteric margins}

NET: neuroendocrine tumor

\section{Discussion}

Small bowel, which constitutes $75 \%$ of the total length and $95 \%$ of the total surface area of the GI tract, is not a usual source for GI neoplasms due to multiple reasons. The contents of the small bowel are dilute and less irritating to the mucosa, and the transit time is rapid, which means less carcinogenic exposure. Besides, the bacterial count is low, implying that organisms may not be able to convert proto-oncogenes to oncogenes. Also, the small bowel has an abundance of immunoglobulin A containing lymphoid tissue [6]. Of all the small bowel tumors, carcinoid is of particular significance since it can present with obscure gastrointestinal bleeding (OGIB). OGIB, which represents about $5 \%$ of lower GI bleeding, is defined as active GI bleeding where the cause cannot be explained after a normal esophagogastroduodenoscopy and colonoscopy result [7]. The source of such bleed is usually the small bowel, and the common causes vary with age, as shown in Table 1 [7].

Age of the patient

$<20$ years

20-60 years

$>60$ years
Common cause of obscure gastrointestinal bleeding

Meckel diverticulum, $\mathrm{CD}$

Small bowel tumors (GIST, carcinoid), CD, AVM

AVM, small bowel tumor (GIST, carcinoid)

\section{TABLE 1: Most common causes of obscure gastrointestinal bleeding}

CD: Crohn's disease; GIST: gastrointestinal stromal tumor; AVM: arteriovenous malformation

The common causes of lower GI bleeding are shown in Table 2 [8]. 


\section{Cureus}

Causes of lower GI bleed

1. Upper Gl causes

Ulcer

Neoplasm

Vasculitis

2. Small bowel causes

Inflammatory bowel disease

Neoplasm

Arteriovenous malformation

Meckel diverticulum

Mesenteric ischemia

Radiation induced

Infections

Aortoenteric fistula

3. Colorectal causes

Diverticular disease (most common)

Neoplasm

Inflammatory bowel disease

Angiodysplasia

Ischemic colitis

Aortoenteric fistulas

Post-polypectomy

Infections

Radiation induced

TABLE 2: Common causes of lower GI bleeding

Gl: gastrointestinal

NETs of small bowel usually remain asymptomatic for a long time or can present with ill-defined symptoms [2]. The manifestation of the disease becomes more prominent when the tumor spreads to the liver (40\%), or the mass results in acute complications like bowel obstruction, perforation, bleeding, or ischemia [3]. Local complications are due to the hormones produced by the primary tumor, which further leads to widespread mesenteric and peritoneal fibrosis [9]. Metastatic disease to the liver often presents with systemic symptoms such as diarrhea, wheezing, and flushing due to the production of vasoactive peptides like serotonin, vasoactive intestinal peptide, and histamine [10,11]. A retrospective analysis was conducted in Massachusetts on adult patients with histologically proven small bowel NETs. In that study, the majority of the patients presented with OGIB and anemia (87.5\%) [12], and the leading cause of mortality was liver failure ( $80 \%$ ) followed by bowel obstruction in $16 \%$ of the cases [9].

The initial workup of NETs consists of a CT and magnetic resonance imaging of the abdomen/pelvis $[12,13]$. However, despite having good sensitivity and specificity, their role in diagnosing NETs of the small bowel is often limited [13]. In the past decade, video capsule endoscopy (VCE) has emerged as an important test in diagnosing small bowel NETs $[12,14]$. In a retrospective analysis by Noujaim et al., the findings on VCE, including tumor location, morphology, and number, correlated with the findings obtained during surgery [12]. Furthermore, a meta-analysis by Triester et al. done on 88 patients with OGIB revealed that VCE was able to detect the source of bleeding in $67 \%$ of the patients [14]. These results are in contrast to the $8 \%$ of cases detected by small bowel radiographic studies. A study by Hakim et al. proposed that CT enterography 
can help identify NETs that were missed on VCE [15]. However, there is still some discrepancy between what is detected on imaging and what is observed intraoperatively [3]. NETs are usually diagnosed late, with the majority presenting with metastases to liver and lymph nodes (85.5\%) [3]. Interestingly, the primary tumor often remains small. The American College of Gastroenterology guidelines in approaching a case of obscure GI bleeding is shown in Figure 2 [16,17].

1.Obtain detailed patient history with emphasis on ruling out malabsorption and hematological causes of anemia 2.Search for objective evidence of GI bleed

Suspicion of GI bleed

1. Esophagogastroduodenoscopy and/or colonoscopy

2. Imaging tests: $\mathrm{CT}$ arterial portography

If negative

Further testing including:

1. CT enterography

2. Video capsule endoscopy

3. Balloon-assisted endoscopy

FIGURE 2: ACG guidelines for obscure GI bleeding

ACG: The American College of Gastroenterology; GI: gastrointestinal; CT: computerized tomography

Management of the tumors is dependent on the size and location of the lesion. Duodenal NETs that are $<1$ $\mathrm{cm}$ can be removed through an endoscope as they are often isolated masses with no metastasis. In contrast, jejunoileal tumors often require surgery and present with early metastasis to lymph nodes and liver [2]. Ki67 index, a histopathological marker, helps in tumor grading. A higher index signifies an aggressive tumor growth. According to the World Health Organization (WHO) classification of 2017, grade 1/grade2 (G1/G2) tumors have a Ki-67 index of 0\%-20\%, and grade 3 (G3) has an index of >20\% (Table 3) [3,18]. For G1 tumors, regardless of liver involvement, surgical resection of the primary tumor with radical lymph node dissection has shown survival benefit [3,9]. In contrast, for G2 tumors, data are less supportive of surgery benefit, and it is usually not recommended unless for symptomatic palliative relief [3]. For liver metastasis, management consists of surgical resection, even if the entire metastatic tumor cannot be eradicated. This is due to the fact that NETs produce vasoactive amines that precipitate liver failure (the leading cause of mortality), and tumor resection helps in preventing or at least slowing down the progression of liver failure [9]. In a cohort study conducted in Germany, the investigators observed that patients who had an R0 or R1 resection of their hepatic metastasis fared better with a five-year survival rate of $88.5 \%$ compared to $69.1 \%$ five-year survival rate in those who underwent $\mathrm{R} 2$ resection or no liver resection at all [3]. 


\section{Cureus}

\section{WHO 2017 grading of NETs}

Tumor grade

Mitoses/10 HPF

Ki-67 index

Well differentiated

G1

$<2$

$<3$

G2

2 to 20

3 to 20

G3

$>20$

$>20$

Poorly differentiated

G3

$>20$

$>20$

\section{TABLE 3: WHO 2017 grading of NET}

WHO: World Health Organization; NET: neuroendocrine tumor; G: grade; HPF: high-power field

Currently, immunotherapy is emerging to be a thriving option in the management of patients with GI and pancreatic NETs [19]. In the past, somatostatin analogs and interferon-alpha have shown to improve the quality of life and survival in these patients [20]. Various immunoproteins like cytotoxic T-lymphocyteassociated protein 4 (CTLA-4) and programmed cell death-1 (PD-1)/programmed death-ligand 1 (PD-L1) are being targeted to reveal their benefits in patients with GI NETs [19]. Biotherapy is still emerging, and it is expected to unveil better benefits not only for NETs but also for many other cancers. Several clinical trials are underway, focusing on the potential benefits of biotherapy alone and in combination with chemotherapy as well (Table 4) [20].

\begin{tabular}{|c|c|c|c|c|}
\hline Study & $\begin{array}{l}\text { Trial } \\
\text { phase }\end{array}$ & Drug & Mechanism of action & Conditions \\
\hline $\begin{array}{l}\text { lbrutinib in advanced } \\
\text { carcinoid and pancreatic } \\
\text { neuroendocrine tumors }\end{array}$ & $\begin{array}{l}\text { Phase } \\
\text { II }\end{array}$ & Ibrutinib & $\begin{array}{l}\text { Inhibits Bruton's tyrosine kinase and hence B- } \\
\text { cell receptor signaling }\end{array}$ & $\begin{array}{l}\text { Carcinoid tumors, } \\
\text { pancreatic } \\
\text { neuroendocrine } \\
\text { tumors }\end{array}$ \\
\hline $\begin{array}{l}\text { Fosbretabulin in subjects } \\
\text { with pancreatic or Gl } \\
\text { neuroendocrine tumors with } \\
\text { elevated biomarkers }\end{array}$ & $\begin{array}{l}\text { Phase } \\
\text { II }\end{array}$ & $\begin{array}{l}\text { Fosbretabulin } \\
\text { tromethamine }\end{array}$ & $\begin{array}{l}\text { Destabilizes microtubules and targets tumor } \\
\text { vasculature thus inhibiting angiogenesis }\end{array}$ & $\begin{array}{l}\text { Neuroendocrine } \\
\text { tumors }\end{array}$ \\
\hline $\begin{array}{l}\text { Nivolumab with ipilimumab } \\
\text { in subjects with } \\
\text { neuroendocrine tumors }\end{array}$ & $\begin{array}{l}\text { Phase } \\
\text { II }\end{array}$ & $\begin{array}{l}\text { Nivolumab and } \\
\text { ipilimumab }\end{array}$ & $\begin{array}{l}\text { Inhibits immune responses through PD-1 } \\
\text { pathway. ipilimumab binds to CTLA- } 4 \text { and } \\
\text { blocks the normal inhibitory signal thus } \\
\text { allowing CTLs to destroy cancer cells }\end{array}$ & $\begin{array}{l}\text { Neuroendocrine } \\
\text { tumors, carcinoid } \\
\text { tumors }\end{array}$ \\
\hline $\begin{array}{l}\text { The MetNET-2 trial (MetNET- } \\
\text { 2) }\end{array}$ & $\begin{array}{l}\text { Early } \\
\text { phase } \\
\text { I }\end{array}$ & $\begin{array}{l}\text { Lanreotide and } \\
\text { metformin }\end{array}$ & $\begin{array}{l}\text { Lanreotide: somatostatin analog; metformin } \\
\text { anti-diabetic agent, recently emerged as anti- } \\
\text { tumor agent; acts through modification of } \\
\text { systemic metabolism or through cell pathway } \\
\text { effects }\end{array}$ & $\begin{array}{l}\text { Neuroendocrine } \\
\text { tumors }\end{array}$ \\
\hline $\begin{array}{l}\text { Nintedanib in patients with } \\
\text { locally advanced or } \\
\text { metastatic neuroendocrine } \\
\text { tumors }\end{array}$ & $\begin{array}{l}\text { Phase } \\
\text { II }\end{array}$ & Nintedanib & $\begin{array}{l}\text { Inhibits growth factors through inhibition of } \\
\text { tyrosine kinase }\end{array}$ & $\begin{array}{l}\text { Carcinoid tumor, } \\
\text { metastatic carcinoid } \\
\text { tumor, } \\
\text { neuroendocrine } \\
\text { neoplasms }\end{array}$ \\
\hline $\begin{array}{l}\text { Everolimus and octreotide in } \\
\text { patients with advanced } \\
\text { carcinoid tumor (RADIANT-2) }\end{array}$ & $\begin{array}{l}\text { Phase } \\
\text { III }\end{array}$ & $\begin{array}{l}\text { Octreotide vs } \\
\text { octreotide+everolimus }\end{array}$ & $\begin{array}{l}\text { Octreotide: somatostatin analog, everolimus: } \\
\text { inhibits mTOR }\end{array}$ & $\begin{array}{l}\text { Carcinoid tumor, } \\
\text { malignant carcinoid } \\
\text { syndrome }\end{array}$ \\
\hline $\begin{array}{l}\text { Carfilzomib in patients with } \\
\text { advanced neuroendocrine } \\
\text { cancers }\end{array}$ & $\begin{array}{l}\text { Phase } \\
\text { II }\end{array}$ & Carfilzomib & Selectively inhibits proteosomes & $\begin{array}{l}\text { Neuroendocrine } \\
\text { cancers }\end{array}$ \\
\hline
\end{tabular}




\section{Cureus}

Combination chemotherapy plus interferon-alpha followed by filgrastim in patients with GI tumors
Biological agent: filgrastim

Phase Recombinant II interferon-alpha drugs: fluorouracil and hydroxyurea
Phase Telotristat etiprate

III tablets treatment for patients with carcinoid syndrome symptoms (TELEPATH)

Veliparib, capecitabine, and temozolomide in patients with advanced, metastatic, and recurrent Phase I Capecitabine, neuroendocrine tumor

Erlotinib hydrochloride and cetuximab in patients with advanced gastrointestinal cancer, head and neck cancer, non-small cell lung cancer, or colorectal cancer chemotherapy agents
Filgrastim: colony-stimulating factor; helps body make white blood cells. Recombinant interferon-alpha: therapeutic peptide, at molecular level to exert anti-viral and antitumor effects. Flourouracil: anti-metabolite, anti-neoplastic agent. Hydroxyurea: antimetabolite, slows cancer growth

Inhibits tryptophan hydroxylase

Extrahepatic bile duct cancer, gastric cancer, gastrointestinal carcinoid tumor, liver cancer, pancreatic cancer, small intestine cancer

Carcinoid syndrome

Functional pancreatic neuroendocrine

Capecitabine: anti-metabolite, anti-cancer drug. Temozolomide: alkylating anti-cancer drug. Veliparib: inhibits protein PARP; acts at molecular level by blocking PARP and thus allow cancer cells to respond better to other

tumor, metastatic carcinoid tumor, somatostatinproducing neuroendocrine tumors

Metastatic gastrointestinal carcinoid tumors, recurrent colon cancer, recurrent gastrointestinal carcinoid tumors

\section{TABLE 4: List of various biotherapy clinical trials}

PD-1 pathway: programmed death-1 pathway; CTLA-4: cytotoxic T-lymphocyte-associated protein 4; CTL: cytotoxic T-lymphocyte; mTOR: mammalian target of rapamycin; PARP: poly(ADPribose)polymerase; EGFR: epidermal growth factor receptor

\section{Conclusions}

Small bowel carcinoids are rare tumors that present with vague symptoms like GI bleed and anemia. A thorough investigation is required in any case of suspicious GI bleed, especially in older patients over 65 years. Management consists of surgery and various chemotherapy and immunotherapy drugs. Biotherapy is still emerging, and it is expected to unveil better benefits not only for NETs but also for many other cancers.

\section{Additional Information}

\section{Disclosures}

Human subjects: Consent was obtained by all participants in this study. Conflicts of interest: In compliance with the ICMJE uniform disclosure form, all authors declare the following: Payment/services info: All authors have declared that no financial support was received from any organization for the submitted work. Financial relationships: All authors have declared that they have no financial relationships at present or within the previous three years with any organizations that might have an interest in the submitted work. Other relationships: All authors have declared that there are no other relationships or activities that could appear to have influenced the submitted work.

\section{References}

1. Bonekamp D, Raman SP, Horton KM, Fishman EK: Role of computed tomography angiography in detection and staging of small bowel carcinoid tumors. World J Radiol. 2015, 7:220-235. 10.4329/wjr.v7.i9.220

2. Kunovský L, Dastych M, Robek O, et al.: Multiple neuroendocrine tumor of small bowel : a case report and a review of literature. Vnitr Lek. 2018, 64:966-969.

3. Watzka FM, Fottner C, Miederer M, et al.: Surgical treatment of NET of small bowel: a retrospective analysis. World J Surg. 2016, 40:749-758. 10.1007/s00268-016-3432-2

4. Oronsky B, Ma PC, Morgensztern D, Carter CA: Nothing but NET: a review of neuroendocrine tumors and carcinomas. Neoplasia. 2017, 19:991-1002. 10.1016/j.neo.2017.09.002 
5. Bilimoria KY, Bentrem DJ, Wayne JD, Ko CY, Bennett CL, Talamonti MS: Small bowel cancer in the United States: changes in epidemiology, treatment,and survival over the last 20 years. Ann Surg. 2019, 249:63-71. 10.1097/SLA.0b013e31818e4641

6. Negoi I, Paun S, Hostiuc S, et al.: Most small bowel cancers are revealed by a complication . Einstein (Sao Paulo). 2015, 13:500-505. 10.1590/S1679-45082015A03380

7. Cotter TG, Buckley NS, Loftus CG: Approach to the patient with hematochezia. Mayo Clin Proc. 2017, 92:797-804. 10.1016/. mayocp.2016.12.021

8. Tringali A: Endoscopic management of acute lower gastrointestinal bleeding . J Gastroenterol Hepatol Res. 2015, 4:1486-1500.

9. Farley HA, Pommier RF: Surgical treatment of small bowel neuroendocrine tumors . Hematol Oncol Clin North Am. 2016, 30:49-61. 10.1016/j.hoc.2015.09.001

10. Thomas AM, Beumer JD, Suppiah A, Devitt PG: Unusual cause of gastrointestinal bleeding: multiple small bowel carcinoid tumours. ANZ J Surg. 2017, 87:100-101. 10.1111/ans.12853

11. Strosberg J: Neuroendocrine tumours of the small intestine. Best Pract Res Clin Gastroenterol. 2012, 26:755773. 10.1016/j.bpg.2012.12.002

12. Noujaim MG, Green J, Min M, et al.: Carcinoids and capsules: a case series highlighting the utility of capsule endoscopy in patients with small bowel carcinoids. Gastroenterology Res. 2017, 10:347-351. 10.14740/gr937w

13. ElGuindy YM, Javadi S, Menias CO, Jensen CT, Elsamaloty H, Elsayes KM: Imaging of secretory tumors of the gastrointestinal tract. Abdom Radiol. 2017, 42:1113-1131. 10.1007/s00261-016-0976-4

14. Triester SL, Leighton JA, Leontiadis GI, et al.: A meta-analysis of the yield of capsule endoscopy compared to other diagnostic modalities in patients with obscure gastrointestinal bleeding. Am J Gastroenterol. 2005, 100:2407-2418. 10.1111/j.1572-0241.2005.00274.x

15. Hakim FA, Alexander JA, Huprich JE, Grover M, Enders FT: CT-enterography may identify small bowel tumors not detected by capsule endoscopy: eight years experience at Mayo Clinic Rochester. Dig Dis Sci. 2011, 56:2914-2919. 10.1007/s10620-011-1773-0

16. Fisher L, Krinsky ML, Anderson MA, et al.: The role of endoscopy in the management of obscure GI bleeding. Gastrointest Endosc. 2010, 72:471-479. 10.1016/j.gie.2010.04.032

17. Teh JW, Fowler AL, Donlon NE, et al.: Obscure gastrointestinal bleeding resulting from small bowel neoplasia: a case series. Int J Surg Case Rep. 2019, 60:87-90. 10.1016/j.ijscr.2019.05.006

18. Choe J, Kim KW, Kim HJ, et al.: What is new in the 2017 World Health Organization Classification and 8th American Joint Committee on Cancer staging system for pancreatic neuroendocrine neoplasms? Korean J Radiol. 2019, 20:5-17. 10.3348/kjr.2018.0040

19. Oberg K: Chemotherapy and biotherapy in neuroendocrine tumors . Curr Opin Oncol. 1993, 5:110-120.

20. Papaxoinis G, Syrigos K, Saif MW: New concepts in the treatment strategy of neuroendocrine tumors: the role of biotherapy. Discov Med. 2016, 23:381-389. 